\title{
PERANCANGAN SISTEM INFORMASI PRODUKSI DAN PENJUALAN PADA UMKM BAKPIA (STUDI KASUS AA BAKERY)
}

\author{
Marinda Nurul Ilmi ${ }^{1)},{ }^{*}$ Farindika Metandi ${ }^{2)}$ \\ ${ }^{1)}$ Akuntansi, Politeknik Negeri Samarinda. \\ ${ }^{1)}$ Teknik Informatika, Politeknik Negeri Samarinda \\ email: marindanilmi@gmail.com ${ }^{1)}$, farindika@polnes.ac.id ${ }^{2)}$ \\ ( ${ }^{*}$ penulis korespondensi)
}

\begin{abstract}
Abstrak,-Penelitian ini bertujuan untuk merancang Sistem Informasi Produksi dan Penjualan pada UMKM Bakpia dengan studi kasus AA Bakery. AA Bakery merupakan UMKM yang bergerak di bidang produksi dan distribusi. Usaha ini memproduksi bakpia dan produk lainnya dalam jumlah besar namun belum menerapkan pencatatan terhadap stok bahan maupun stok produk, sehingga diperlukan sebuah sistem informasi untuk membantu dalam pencatatan stok bahan dan produk. Perancangan sistem informasi untuk AA Bakery menggunakan alat analisis yakni alur bisnis usaha, yang telah digambarkan dalam bentuk desain sistem DFD level 0 (Context Diagram), DFD level 1, dan ER-Diagram. Pada penelitian ini telah dihasilkan dokumen cetak biru untuk pengembangan sistem informasi produksi dan penjualan pada UMKM Bakpia.
\end{abstract}

Kata kunci :- Sistem Informasi Penjualan, ERD, DFD, UMKM

\section{PENDAhUluAN}

Peningkatan kesejahteraan menjadi tujuan dari seluruh manusia, khususnya masyarakat di Indonesia. Tak jarang mereka memilih untuk membuka sebuah bisnis/usaha. Indonesia memiliki berbagai jenis kegiatan bisnis, salah satunya dalam skala mikro, kecil, dan menengah, atau disebut UMKM (Usaha Mikro, Kecil, dan Menengah). Meski dengan skala yang belum besar, namun sebagian bisnis berbasis UMKM ini sudah mampu menghasilkan keuntungan yang besar.

Jika usaha dengan skala UMKM sudah mampu mendapatkan penghasilan yang besar, maka usaha ini juga mengeluarkan biaya yang tidak sedikit, namun masih dengan prinsip menekan pengeluaran biaya menjadi seminimum mungkin. Hal inilah yang mengakibatkan banyaknya transaksi yang terjadi. Beragam transaksi yang terjadi pada bisnis UMKM memerlukan bantuan teknologi informasi berupa komputer, agar pekerjaan-pekerjaan yang tidak dapat dilakukan dalam waktu singkat dapat dilakukan dengan lebih mudah, khususnya dalam mengolah data berbentuk angka.

Pada kasus ini, perusahaan UMKM yang menjadi objek penelitian penulis yaitu AA Bakery masih menggunakan sheet di Microsoft Excel untuk menyelesaikan pekerjaan dalam bidang administrasi. Oleh karena itu, perlu dilakukan pembenahan dalam pengelolaan data-data pada perusahaan ini, mengingat pendapatan yang dihasilkan oleh perusahaan ini tergolong cukup besar, sehingga sangat disayangkan apabila pengelolaan datanya masih belum dilakukan dengan baik. Jika tidak segera diperbaiki, dikhawatirkan suatu saat terjadi penyelewengan data dalam perusahaan ini, contohnya seperti penjualan fiktif. Apabila data-data yang terkait dengan pendapatan dan pengeluaran perusahaan ini diolah secara maksimal, maka akan didapat informasi yang lebih relevan.

Oleh sebab itu, penulis melakukan penelitian terkait alur transaksi pada perusahaan ini, dan selanjutnya merancang sebuah aplikasi yang dapat mengotomatisasi data-data yang diproses sesuai alur transaksi yang terjadi. Alur transaksi perlu diteliti sebab pada alur ini dapat diketahui dari mana data tersebut berasal dan ke transaksi mana data tersebut ditujukan. Selain itu, dari alur transaksi juga dapat diketahui hubungan antara satu transaksi dengan transaksi lainnya. Kemudian, pengotomatisasian pengolahan data akan membantu mempercepat pengolahan data menjadi informasi, serta meminimalisir kemungkinan terjadinya penyelewengan terhadap data sehingga informasi yang didapatkan menjadi lebih relevan dan akurat.

\section{TINJAUAN PUSTAKA}

\subsection{Informasi}

Informasi adalah data yang diolah menjadi bentuk yang lebih berguna dan lebih berarti bagi penerimanya. Sumber informasi adalah data. Data kenyataan yang menggambarkan suatu kejadiankejadian dan kesatuan nyata. Kejadian-kejadian (event) adalah kejadian yang terjadi pada saat 
tertentu. Definisi lain dari Informasi adalah data yang telah diolah menjadi suatu bentuk yang penting bagi si penerima dan mempunyai nilai nyata atau yang dapat dirasakan dalam keputusan-keputusan yang sekarang atau keputusan-keputusan yang akan datang.

Fungsi utama informasi, yaitu : menambah pengetahuan atau mengurangi ketidakpastian pemakai informasi, karena informasi berguna memberikan gambaran tentang suatu permasalahan sehingga pengambil keputusan dapat menentukan keputusan lebih cepat, informasi juga memberikan standar, aturan maupun indikator bagi pengambil keputusan[1].

\subsection{Sistem}

Didalam mendefinisikan sistem terdapat dua kelompok pendekatan, yaitu pendekatan yang menekankan pada prosedurnya dan pendekatan yang menekankan pada komponen atau elemennya. Pendekatan sistem yang lebih menekankan pada prosedur, mendefinisikan sistem sebagai suatu jaringan kerja dari prosedur-prosedur yang saling berhubungan, berkumpul bersama-sama untuk melakukan suatu kegiatan atau untuk menyelesaikan suatu sasaran tertentu[2].

Sedangkan pendekatan sistem yang lebih menekankan pada elemennya atau komponennya, mendefinisikan sistem sebagai kumpulan elemenelemen yang berinteraksi untuk mencapai suatu tujuan tertentu[2].

Sistem juga dapat didefinisikan sebagai suatu susunan yang teratur dari kegiatan-kegiatan yang saling tergantung dan prosedur-prosedur yang saling berhubungan yang melaksanakan dan mempermudah kegiatan organisasi.

\subsection{Penjualan}

Penjualan adalah penerimaan yang diperoleh dari hasil penjualan produk seperti pengiriman barang (goods) atau pemberian jasa (service) yang diberikan[3].

Penjualan adalah jumlah omzet barang atau jasa yang dijual, baik dalam unit maupun rupiah[4]. Berdasarkan beberapa definisi tersebut, dapat disimpulkan bahwa penjualan adalah berkumpulnya seorang pembeli dan penjual dengan tujuan melaksanakan tukar menukar barang dan jasa berdasarkan pertimbangan yang berharga.

\subsection{Data Flow Diagram (DFD)}

Diagram Alir Data (DAD)/ Data Flow Diagram (DFD) adalah suatu diagram yang menggunakan notasi-notasi untuk menggambarkan arus dari data sistem, yang penggunaannya sangat membantu untuk memahami sistem secara logika, tersruktur dan jelas.
DFD merupakan alat bantu dalam menggambarkan atau menjelaskan DFD ini sering disebut juga dengan nama Bubble chart, Bubble diagram, model proses, diagram alur kerja, atau model fungsi.menggambarkan atau menjelaskan DFD ini sering disebut juga dengan nama Bubble chart, Bubble diagram, model proses, diagram alur kerja, atau model fungsi[5].

\subsection{Entity Relationship Diagram (ERD)}

Entity Relationship Diagram (ERD) adalah bentuk paling awal dalam melakukan perancangan basis data relasional. ERD digunakan untuk pemodelan basis data relasional[6].

Entity Relationship Diagram (ERD) merupakan tools yang digunakan untuk memodelkan struktur data dengan menggambarkan entitas dan hubungan antara entitas (Relationship) secara abstrak (konseptual)[7].

Dari kedua definisi di atas, dapat disimpulkan bahwa ERD merupakan bentuk paling awal yang digunakan untuk memodelkan struktur data dengan yang menggambarkan antara entitas dan hubungan antar entitas.

\subsection{Usaha Mikro, Kecil, dan Menengah (UMKM)}

Menurut Badan Pusat Statistik (BPS) definisi UMKM berdasarkan kuantitas tenaga kerja, yaitu usaha kecil merupakan usaha yang memiliki jumlah tenaga kerja 5 orang sampai dengan 19 orang, sedangkan usaha menengah merupakan usaha yang memiliki jumlah tenaga kerja 20 orang sampai dengan 99 orang.

Menurut Kementrian Keuangan, berdasarkan Keputusan Menteri Keuangan Nomor 316/KMK 016/1994 tanggal 27 Juni 1994 bahwa Usaha Kecil sebagai perorangan/badan usaha yang telah melakukan kegiatan /usaha yang mempunyai penjualan/omset per tahun setinggi-tingginya $\mathrm{Rp}$ 600.000.000 atau asset (aktiva) setinggi-tingginya Rp 600.000.000 (diluar tanah dan bangunan yang ditempati).

Berdasarkan beberapa definisi tersebut, dapat disimpulkan bahwa pengertian UMKM dapat dilihat dari berbagai aspek, baik dari segi kekayaan yang dimiliki pelaku usaha, jumlah tenaga kerja yang dimiliki atau dari segi penjualan/omset pelaku UMKM.

\section{METODE}

Dalam pemaparan yang disampaikan di atas peneliti tertarik untuk merancang suatu sistem informasi produksi dan penjualan pada UMKM Bakpia. Adapun proses yang akan dilakukan pada penelitian ini dapat dilihat pada Gambar 1. 


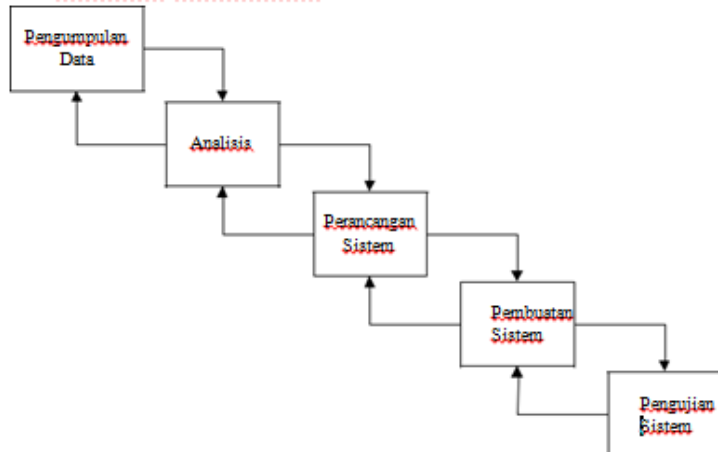

Gambar 1. Waterfall model dalam penelitian

Fokus dari penelitian ini antara lain:

1. Tahap pertama adalah melakukan identifikasi masalah dan pengumpulan data-data yang diperlukan didalam perancangan sistem.

2. Tahap kedua adalah melakukan analisis kebutuhan berdasarkan dari data dan fakta yang diperoleh.

3. Tahap ketiga adalah melakukan perancangan berdasarkan hasil analisis di tahap kedua.

\section{HASIL DAN PEMBAHASAN}

Hasil dari penelitian ini adalah berupa sebuah rancangan sistem informasi yang diharapkan dapat dimanfaatkan oleh UMKM Bakpia pada AA Bakery ketika akan mengembangkan Sistem Informasi Produksi dan Penjualan Bakpia pada UMKM Bakpia AA Bakery.

Perancangan menggunakan Data Flow Diagram (Gambar 2 dan Gambar 3) dan Entity Relationhip Diagram seperti yang diberikan pada Gambar 4 .

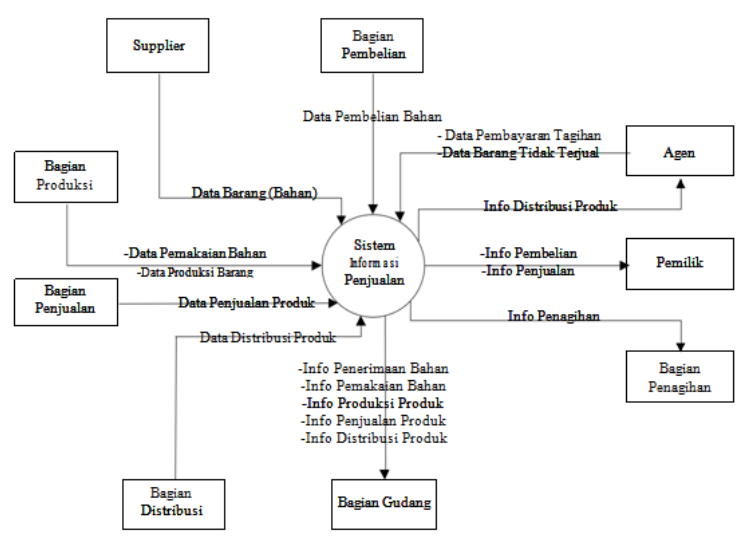

Gambar 2. Context Diagram

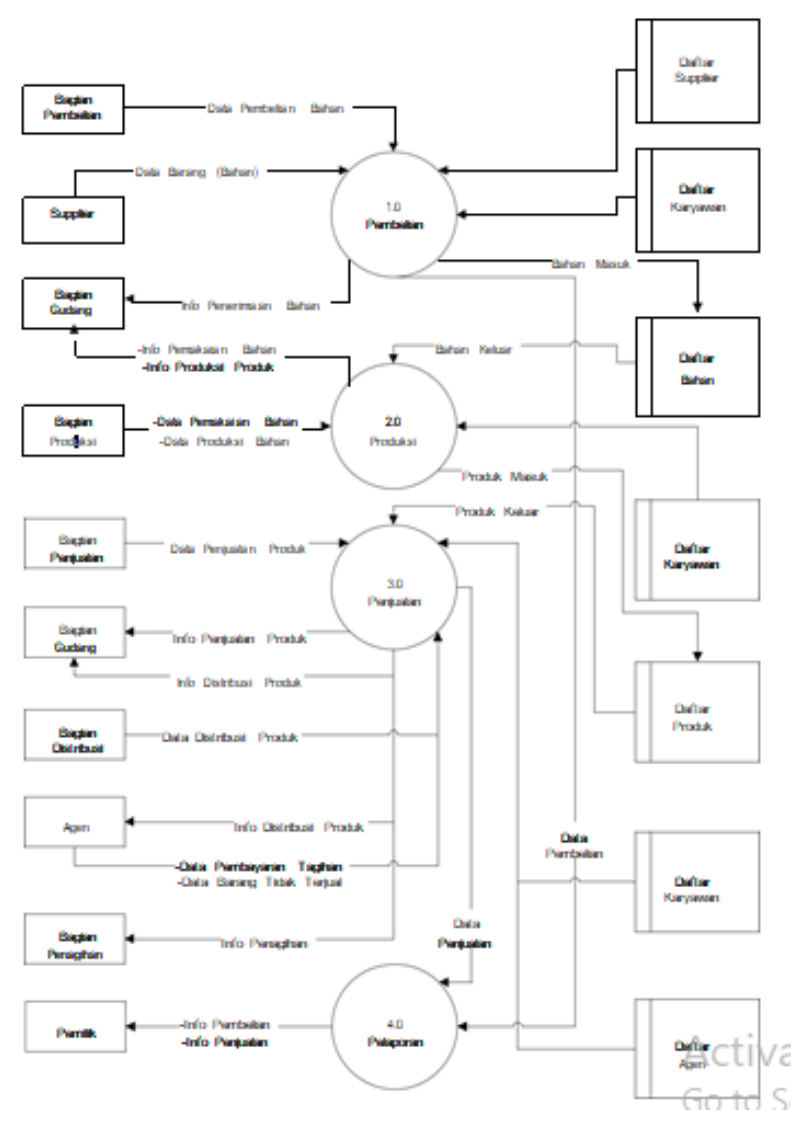

Gambar 3. DFD Level 1

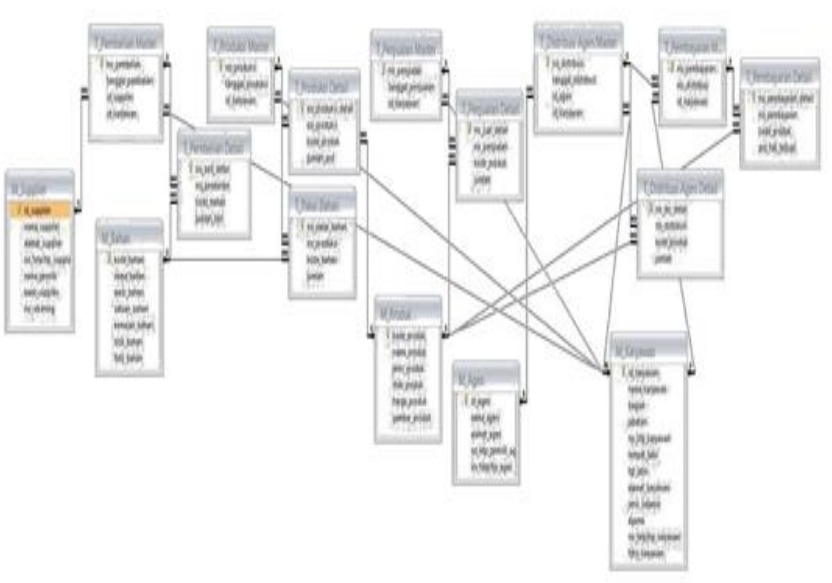

Gambar 4. ERD 
JUST TI Volume 12 Nomor 1, Januari 2020 : 17 - 20

ISSN: 2579-4510(online) ISSN: 2085-6458(print)

\section{KESIMPULAN DAN SARAN}

Berdasarkan hasil perancangan sistem informasi produksi dan penjualan pada UMKM Bakpia (Studi Kasus AA Bakery), maka dapat disimpulkan sebagai berikut:

1. Perancangan dimulai dengan merancang tabeltabel data induk yang sesuai dengan keperluan pemrosesan transaksi pada AA Bakery, terdiri dari data bahan, data produk, data karyawan, data supplier, dan data agen; dan merancang tabel-tabel transaksi berisi informasi yang diperlukan oleh AA Bakery yang terdiri dari transaksi pembelian bahan, transaksi produksi, transaksi penjualan produk, transaksi distribusi produk, dan transaksi penagihan distribusi.

2. Jika rancangan Sistem informasi produksi dan penjualan pada UMKM Bakpia (Studi Kasus AA Bakery) dapat dikembangkan maka diharapkan dapat memudahkan pengelolaan data dari yang sebelumnya masih menggunakan metode manual, kemudian dapat diaplikasikan sehingga akan menambah kinerja UMKM Bakpia AA Bakery dalam mengelola kegiatan Produksi dan Penjualan menjadi lebih baik

Adapun saran yang dapat disampaikan oleh penulis dalam penelitian perancangan sistem informasi produksi dan penjulana pada UMKM Bakpia (Studi Kasus AA BAKERY) adalah sebagai berikut:

1. Sebaiknya hasil dari perancangan ini dapat dijadikan acuan didalam pengembangan sistem informasi produksi dan penjualan pada UMKM Bakpia (Studi Kasus AA BAKERY).

2. Pengembangan sistem informasi sebaiknya menggunakan teknologi berbasis web untuk menjangkau pasar yang lebih luas dan kemudahan didalam pengelolaan data pada perusahaan.

3. Bagi peneliti selanjutnya, agar pengembangan sistem informasi dapat ditambah dengan fasilitas-fasilitas yang menyajikan hal-hal berikut:

a. Penentuan harga jual bagi masingmasing produk menyesuaikan dengan harga bahan yang fluktuatif.

b. Pengaruh penentuan nilai jual terhadap keuntungan/kerugian dari penggunaan bahan dalam kegiatan produksi.

\section{REFERENSI}

[1] Hutahean, J. (2014). Konsep Sistem Informasi. Yogyakarta: Deepublish.

[2] Moekijat., R.,1996. Pengantar Sistem Informasi Manajemen, CV. Remaja Karya, Bandung.

[3] Fahmi, Irham. 2017. Analisis Laporan Keuangan. Bandung: Penerbit Alfabeta

[4] Kasmir. 2018. Analisis Laporan Keuangan. Jakarta: PT Bumi Aksara

[5] Jogiyanto, H. (2005). Analisa dan Desain Informasi. Yogyakarta.

[6] Sukamto, Rosa Ariani dan M. Shalahuddin. 2016. Rekayasa Perangkat Lunak. Bandung: Informatika Bandung

[7] Mulyani, Sri. 2016. Metode Analisis dan Perancangan Sistem. Bandung: Abdi Sistematika 